Kalis. Es bleiben sonach noch $2-0,544=1,456$ Unzen Kalkhydrat übrig, um aus dem vorhandenen schwefelsauren Ammoniak das Ammoniak auszutreiben. Wäre das benutzte Kalkhydrat wasserärmer als $\mathrm{CaO}, \mathrm{HO}$, so stellte sich die Menge des ätzend bleibenden Kalks noch grösser heraus.

5) Mit der Annahme, dass $\mathrm{H}$ ahnemann's Causticum eine sehr verdiunnte Ammoniakfliussigkeit sei, stimmen auch die von Habnemann demselben beigelegten physischen und chemischen Eigenschaften überein.

\title{
Ueber Extracte;
}

von

Dr. Geiseler, Apotheker in Königsberg i. d. Neumark.

Die Bereitung der Extracte, so einfach sie erscheint, ist unstreitig eine der wichtigsten pharmaceutischen Operationen. Es ist bekannt, dass die Bereilungsweise der Extracte, dieser wirksamen Heilmittel, in der 6ten Auflage der Preuss. Pharmakopöe, mannigfache Abänderungen erlitten hat, die sich gewiss allgemeinen Beifall erworben haben. Dahin gehört namenllich das Ausziehen der Vegetabilien durch Infusion, was sonst in vielen Fällen durch Kochen geschah; ferner das Abdampfen der Ausziuge bei niedrigerer Temperatur im Dampf- und Wasserbade, namentlich aber das beständige Rühren während des Abdampfens, welches die Verdampfung ungemein abkürzı, die Verdampfungszeit und die Berührung mit der Luft also vermindert und die stärkere Erhitzung an den Wänden der Abdampfgefässe verhindert.

Bei der Abdampfung der Flüssigkeiten behufs Darstellung der narkotischen Extracte ist indessen eine Tem. peratur vorgeschrieben, die sich weder im Dampf- noch im Wasserbade genau einhalten lasst. Man hat emplohlen, ein IVasserbadgefass auf das andere zu setzen und auf 
das erste das Abdampfgefäss zu bringen; allein dies Mittel erfüllt den $Z$ weck nicht, die Temperatur wird höher und man ist genöthigt, beständig das Thermometer in der Flüssigkeil hangen zu lassen, und das Feuer bald zu bedecken bald anzuschüren. Am besten lässt sich noch die Temperalur dadurch reguliren, dass man den Kessel, in welchem das Wasser kocht, mil einem Ring-Apparat bedeckt und durch Herausnehmen ciniger Ringe eine geringere Fläche des Bodens de:s Abdampfgefässes den Dämpfen aussetzt. Diese Fläche muss grösser sein, wenn in dem Abdampfgefäss viel, kleiner, wenn in demselben wenig Flüssigkeit enthalten ist. Bei den meisten genau nach der neuen Preuss. Pharmakopöe bereiteten narkotischen Extracten habe ich die Erfahrung gemacht, dass sie in hohem Grade hygroskopisch sind; sie verlieren, wahrscheinlich doch durch Wasseranziehung, ihre stärkere Consistenz und werden dünnflüssiger. Bei den nach der 5ten Auflage der Pr. Pharm. bereiteten Extracten habe ich diese Bemerkung niemals gemacht. Von den nach der s̈ten Auflage der Pr. Pharm. dargestellten narkotischen Extracten hörte man bald, dass sie energischer auf den Organismus einwirkten, als die nach der dritten Auflage der Pharmakopöe durch blosses Abdampfen des ausgepressten Saftes der narkotischen Kräuter bereiteten Extracte; die nach der 6ten Auflage dargestellien erweisen sich wiederum schwächer in ihrer Wirkung, als die nach der blen Auflage bereiteten, wie ich dies namentlich in Bezug auf Extr. Hyoscyami von mebreren älicren Acrzten gehört habe, die jetzt das Extr. Hyosc. in viel grösseren Gaben anwenden als früher. Bei der Vorschrift zur Darstellung der narkotischen Extracte in der 5ten Auflage der Preuss. Pharm. ist nur von einem Evaporiren im Dampfbade ohne Bestimmung der Temperatur die Rede; es scheint also nicht, als wenn eine so niedrige Temperatur, wie sie die 6te Auflage der Pharmakopöe vorschreibt, durchaus nothwendig wäre, um den Extracten ihre Wirksamkeit zu erhalten; doch sind wir vorläufig durch die gegebene Vorsclurift gebunden. 
Ueber die Darstellung der trocknen narkolischen Extracte habe ich mich weitläufiger in dies. Archiv (Bd.61. p. 3I-44) ausgesprochen; der von mir vorgeschlagene Zusatz von Suissholzpulver ist gesetzlich eingefiuhr. In der 6ten Auflage der Pr. Pharm. aber ist die Zahl der Extracte überhaupt, die nur im getrockneten und gepul. verten Zustande vorräthig gehalten werden sollen, bedeutend vermehrt. 12 Extracte sollen in Pulverform vorräthig sein: Extr. Aloes, Extr. Chinae, Extr. Colocynthid., Extr. Columbo, Extr. Ipecacuanhae, Extr. Myrrhae, Extr. N. Vom. aq., Extr. N. Vom. spirit., Extr. Opii, Extr. Rhei, Extr. Rhei comp., Extr. Scillae. Von diesen lassen sich leicht zur Trockne und in Pulverform bringen und erhalten: Extr. Aloes, Extr. Myrrhae, Extr. Noc. Vom. aq. und Extr. Opii, bei den übrigen hat dies aber seine grossen Schwierigkeiten. Ilat man sie, da sie nur bei gelinder Wärme ausgetrocknet werden dürfen, endlich in Pulverform in Gläser gebracht, so laufen sie doch, oft, wenn die Gläser noch gar nicht einmal geöffnet sind, zusammen und die Gläser muissen dann zerbrochen werden, um nur das Extract herauszubekommen, das von neuem getrocknet werden muss. Verluste sind dabei unvermeidlich. Da die genannten Extracte sich, wie ich aus Erfahrung weiss, sehr gut in Pillenconsistenz halten, so würde diese Form gewiss vorzuziehen sein, besonders wenn man erwägt, dass durch das Austrocknen gerade die genannten Extracte manchen Verunreinigungen unterworfen sind. Die Vortheile der leichteren Wägbarkeit und leichteren Auflösbarkeit wiegen die Nachtheile nicht auf.

Noch muss ich bemerken, dass man getadelt hat, dass die Pharmakopöe nicht erlaubt, die mit Weingeist bereiteten Ausziige behufs Abdampfung durch Destillation vom Weingeist zu befreien und diesen so wiederzugewinnen. Dieser Tadel, diinkt mich, ist unbegriindet. Bei der De. stillation wird das Ruihren ausgeschlossen, das von Wichtigkeil ist, weil es verhindert, dass die Auszige an den Wänden des Abdampfgefïsses sich zu slark crhitzen. 